CLINICAL STUDY

\title{
Cardiac function in mild primary hyperparathyroidism and the outcome after parathyroidectomy
}

\author{
$\mathrm{P}_{\text {Farahnak, M Ring }}{ }^{1}, \mathrm{~K}_{\text {Caidahl }}{ }^{1}$, L-O Farnebo ${ }^{2}, \mathrm{M} \mathrm{J} \mathrm{Eriksson}^{1}$ and I-L Nilsson ${ }^{2}$ \\ Section of Surgery, Department of Clinical Science and Education, Karolinska Institutet Södersjukhuset, S-118 83 Stockholm, Sweden, ${ }^{1}$ Section of Clinical \\ Physiology and ${ }^{2}$ Section of Endocrine Surgery, Department of Molecular Medicine and Surgery, Karolinska Institutet, Karolinska University Hospital, \\ SE-17176 Stockholm, Sweden \\ (Correspondence should be addressed to P Farahnak; Email: parastou.farahnak@ki.se)
}

\begin{abstract}
Objective: Primary hyperparathyroidism (PHPT) is associated with cardiovascular morbidity. The extent of cardiovascular abnormalities in patients with mild-asymptomatic disease is unclear. Using sensitive echocardiographic methods, we compared cardiac structure and function in patients with mild PHPT and in healthy controls, and evaluated the changes after parathyroidectomy (PTX).

Methods: In a prospective case-control design, we studied 51 PHPT patients without any cardiovascular risk factors/diseases and 51 healthy matched controls. Cardiac structure, and systolic and diastolic function were evaluated by echocardiography and Doppler tissue imaging (DTI). Blood pressure (BP) and heart rate were measured.

Results: We observed no differences in systolic or diastolic function or in cardiac morphology between the PHPT patients and the age-matched healthy controls. The regional peak systolic myocardial velocities $\left(S^{\prime}\right)$ measured with DTI decreased at all sites $(P<0.05)$ after PTX (tricuspid annulus $14.23 \pm 1.85$ to $13.48 \pm 1.79$, septal $8.48 \pm 0.96$ to $7.97 \pm 0.85$, and lateral $9.61 \pm 2.05$ to $8.87 \pm 1.63 \mathrm{~cm} / \mathrm{s}$, part of the mitral annulus). At baseline, systolic BP was higher in patients compared to controls $(127.6 \pm 17.1$ vs $119.6 \pm 12.6 \mathrm{mmHg}, P<0.05)$. After PTX, both systolic $(127.6 \pm 17.1$ vs $124.6 \pm 16.6 \mathrm{mmHg}, P<0.05)$ and diastolic $(80.3 \pm 9.6$ vs $78.4 \pm 8.6 \mathrm{mmHg}$, $P<0.05)$ BP decreased.

Conclusions: Our results indicate that patients with PHPT without cardiovascular risk factors have a normal global systolic and diastolic function and cardiac morphology. BP and the systolic velocities were marginally reduced after PTX, but reflected the values of the control group. Our findings warrant further investigation of the clinical and prognostic significance of these possibly disease-related inotropic effects.
\end{abstract}

European Journal of Endocrinology 163 461-467

\section{Introduction}

Primary hyperparathyroidism (PHPT) is a common endocrine disorder; in most cases, it is caused by a solitary parathyroid adenoma (1). The prevalence is highest in postmenopausal women, i.e. $3-4 \%$ (2). In recent decades, the clinical profile has shifted towards a less marked symptomatology. Today, the majority of patients with newly diagnosed PHPT show none of the classic symptoms or signs traditionally associated with the disease. The only cure for PHPT is surgical removal of the abnormal parathyroid gland/glands. Although most experts agree that all patients with so-called classic symptoms of PHPT should be offered parathyroidectomy (PTX), there is still a controversy about which patients can be handled conservatively (3).

PHPT has been associated with increased cardiovascular mortality and morbidity. Some of the reported abnormalities are diastolic myocardial dysfunction, left ventricular hypertrophy, hypertension, autonomic imbalance, metabolic disturbances and endothelial vasodilatory dysfunction with varying normalization after PTX (4-11). However, the extent and clinical significance of cardiovascular risk factors coupled to PHPT are matters for discussion. Conflicting data have been reported on the incidence of cardiovascular disorders in mild PHPT (12-15). It has been argued that the risk of cardiovascular complications is coupled to more severe disease (16). Our knowledge of cardiovascular abnormalities in PHPT is mostly based on data from cohorts that include patients with pre-existing cardiovascular risk factors or diseases that may confound the results. The aim of our study was to evaluate cardiac structure and function using echocardiography and Doppler tissue imaging (DTI) in patients with mild PHPT, without cardiovascular risk factors, before and after PTX and in comparison to healthy controls. 


\section{Materials and methods}

\section{Study design}

Analysis was carried out by the intention-to-treat method in a prospective study design. Patients and controls underwent blood analyses, echocardiography, and DTI at baseline, and the patients were re-examined a mean of $15 \pm 4$ months after successful PTX.

\section{Subjects}

The patient population was consecutively recruited from the referrals for parathyroid surgery due to PHPT at the Karolinska University Hospital in Stockholm, Sweden, between January 2006 and November 2008. During the study period, a total of 410 PHPT patients (319 women) were treated with PTX at the clinic. The following inclusion criteria were used: patients with PHPT who fulfilled the criteria for PTX, no history of cardiovascular diseases or any other disease known to affect the cardiovascular system, no medication affecting the cardiovascular system, no diabetes mellitus or renal diseases, no arterial hypertension (defined as systolic blood pressure (SBP) $>140 \mathrm{mmHg}$ and diastolic blood pressure (DBP) $>90 \mathrm{mmHg}$ ), body mass index $(\mathrm{BMI})<28$, and age $>18$ and $<70$ years. Fifty-three patients met the inclusion criteria. After inclusion, two patients were excluded from the study. One woman regretted her decision to undergo PTX. One man underwent parathyroid exploration with the finding of normal parathyroids; later, mutation analysis verified the diagnosis of familial hypocalciuric hypercalcemia. A majority of the patients had no overt symptoms or signs associated with PHPT; except for a history of kidney stone disease $(n=9)$ and bone mineral density below -2.5 at any site $(n=6)$. The healthy control group (age- and gender-matched) was randomly selected from the population registry of the city of Stockholm. They were asked to participate in the study by mail and included if they fulfilled the inclusion criteria described above. Two controls were replaced before entering the study, one because of a high P-parathyroid hormone (PTH) level and the other because of hypertension. Finally, 51 patients and 51 controls (16 men and 35 women) were included in the study. Fifty patients were re-examined with echocardiography and DTI after a mean follow-up time of $15 \pm 4$ months (range 7-28 months); one woman only participated in the blood analyses at follow-up. BMI was calculated by dividing weight $(\mathrm{kg})$ by the square of height $(\mathrm{m})$. Body surface area (BSA) was calculated by the following formula: $\mathrm{BSA}=(0.0001) \times(71.84)$ $\times(\text { weight })^{0.425} \times(\text { height })^{0.725}$, where weight was measured in kilograms and height in centimetres.

Each subject gave written consent to participate in the study, which was approved by the ethics committee of the Karolinska Institute in Stockholm, Sweden.

\section{Laboratory methods}

Biochemical variables were estimated after an overnight fast by anaerobic sampling before and $15 \pm 4$ months after PTX. Clinical routine methods were used to estimate the values for total plasma calcium, albumin, creatinine, glucose, phosphate, TSH (Synchron LX® 20 system, Beckman Coulter Inc., Brea, CA, USA), serum-ionized calcium $\left(\mathrm{Ca}^{++}\right)$(ABL 800, Radiometer, Copenhagen, Denmark), intact plasma PTH (electrochemiluminescense immunoassay on the Modular E system, Roche Diagnostics GmbH, Mannheim, Germany), and pro-brain natriuretic peptide (NT-pro-BNP).

\section{Blood pressure}

Blood pressure (BP) was measured in both arms after at least $30 \mathrm{~min}$ of rest, using an appropriately sized cuff and automatic monitor (Digital Automatic Blood Pressure Monitor, Omron Healthcare Kyoto, Japan). The mean values of systolic and diastolic pressure in the two arms were calculated, and heart rate was noted.

\section{Echocardiography}

All examinations were performed by one experienced echocardiographer, using an ultrasound scanner Vivid 7 (General Electric, Horten, Norway) equipped with DTI capabilities. The patients were placed in the left lateral recumbent position, and the two-dimensional, M-mode, and Doppler echocardiography was performed in accordance with the guidelines of the American Society of Echocardiography (17). All images were stored digitally on an ultrasound database Echopac. Standard echocardiographic measurements included right ventricular end-diastolic diameter, left ventricular (LV) end-diastolic diameter (LVDd) and end-systolic diameter (LVDs), enddiastolic interventricular septum thickness (IVSd), and left ventricular posterior wall thickness (PWTd). The fractional shortening (FS \%), ejection fraction (EF \%), and atrioventricular plane (AV-plane) displacement were calculated from M-mode recordings. LV mass was calculated by the following formula: LVM (grams) $=0.8$ $\left(1.05\left((\text { LVDd + IVSd + PWTd })^{3}-(\text { LVDd })^{3}\right)\right)(18)$. The LV mass was divided by BSA to calculate the LV mass index (LVMI). The cut-off points for LV hypertrophy (LVH) using the LVM/BSA ratio were $150 \mathrm{~g} / \mathrm{m}^{2}$ for males and $120 \mathrm{~g} / \mathrm{m}^{2}$ for females (19). Relative wall thickness (RWT) was calculated according to the following formula: RTW $=(I V S+P W T) / L V D d$. From the calculation of RWT, two geometric patterns of LVH could be established as follows: a concentric pattern, when RWT was $\geq 0.42$, and an eccentric pattern, when RWT $\leq 0.42$ (17). Transmitral inflow and pulmonary venous flow velocities were acquired with pulsed wave Doppler. The velocities of early transmitral diastolic flow $(E)$ and flow velocity during atrial contraction $(A)$, its ratio $(E / A)$, 
Table 1 Clinical and biochemical data (mean \pm s.D.) for healthy controls and for patients with primary hyperparathyroidism (PHPT) before and $15 \pm 4$ months after parathyroidectomy.

\begin{tabular}{|c|c|c|c|c|c|}
\hline \multirow[b]{2}{*}{ Variable } & \multirow[b]{2}{*}{$\begin{array}{c}\text { Controls } \\
n=51\end{array}$} & \multicolumn{2}{|c|}{ PHPT cases } & \multicolumn{2}{|c|}{$P$} \\
\hline & & $\begin{array}{c}\text { Baseline } \\
n=51 \\
\text { (35 females) }\end{array}$ & $\begin{array}{c}\text { Follow-up } \\
n=51 \\
\text { (35 females) }\end{array}$ & $\begin{array}{l}\text { PHPT baseline } \\
\text { versus controls }\end{array}$ & $\begin{array}{l}\text { PHPT baseline } \\
\text { versus follow-up }\end{array}$ \\
\hline Age (years) & $55.2 \pm 8.9$ & $54.3 \pm 8.8$ & $55.6 \pm 8.7$ & & \\
\hline BMI $\left(\mathrm{kg} / \mathrm{m}^{2}\right)$ & $23.4 \pm 2.1$ & $24.1 \pm 2.9$ & $24.7 \pm 3.2$ & NS & $<0.05$ \\
\hline BSA & $1.78 \pm 0.17$ & $1.83 \pm 0.18$ & $1.85 \pm 0.18$ & NS & $<0.05$ \\
\hline Ionized C-calcium (mM/l) & $1.25 \pm 0.04$ & $1.46 \pm 0.07$ & $1.25 \pm 0.05$ & $<0.001$ & $<0.001$ \\
\hline P-Calcium (mM/l) & $2.29 \pm 0.08$ & $2.62 \pm 0.13$ & $2.28 \pm 0.08$ & $<0.001$ & $<0.001$ \\
\hline P-Albumin (g/l) & $38.4 \pm 2.6$ & $39.4 \pm 2.5$ & $38.5 \pm 2.9$ & $<0.05$ & $<0.05$ \\
\hline fP-PTH (ng/l) & $44.1 \pm 12.4$ & $122.6 \pm 43.6$ & $48.8 \pm 15.2$ & $<0.001$ & $<0.001$ \\
\hline P-Phosphate $(\mathrm{mM} / \mathrm{l})$ & $1.1+0.2$ & $0.84+0.2$ & $1.0+0.2$ & $<0.001$ & $<0.001$ \\
\hline P-Creatinine $(\mu \mathrm{M} / \mathrm{l})$ & $69.7 \pm 13.7$ & $67.3 \pm 12.6$ & $69.1 \pm 16.6^{\mathrm{a}}$ & NS & NS \\
\hline fP-Glucose (mM/l) & $5.0 \pm 0.35$ & $5.0 \pm 0.44^{\mathrm{a}}$ & $5.0 \pm 0.51$ & NS & NS \\
\hline P-NT-pro-BNP (ng/l) & $60.4 \pm 35.3^{a}$ & $63.9 \pm 55.1^{\mathrm{a}}$ & $62.8 \pm 50.2^{\mathrm{a}}$ & NS & NS \\
\hline
\end{tabular}

BMI, body mass index; BSA, body surface area.

${ }^{a} n=47-49$.

deceleration time (DT), and isovolumic relaxation time (IVRT) were measured. The maximal left atrial area was traced at end systole in a four-chamber view.

\section{Doppler tissue imaging}

Pulsed Doppler DTI was recorded in the apical four-chamber view at three sites: the tricuspid annulus for the right ventricle (RV) and in the septal and lateral parts of the mitral annulus for the left ventricle (LV). A $3 \mathrm{~mm}$ sampling volume was used. Peak systolic $\left(S^{\prime}\right)$, early diastolic $\left(E^{\prime}\right)$, and late diastolic $\left(A^{\prime}\right)$ velocities recorded by DTI were measured. $E^{\prime} / A^{\prime}$ and $E / E^{\prime}$ for the septal and the lateral part of the mitral annulus were calculated.

\section{Image analyses}

All variables describing cardiac dimensions and structure were analyzed off-line by one observer unaware of the patient's status. The remaining Doppler-derived variables were analyzed by another observer. All measurements were averaged from at least three heartbeats. To assess the measurement variability, the two observers re-measured 20 randomly selected echocardiographic and DTI examinations. The coefficient of variation $(\mathrm{CV})$ was calculated for variables for the determination of inter- and intra-observer variabilities. CV was calculated as the mean percent error, defined as the standard error of the absolute difference between the two sets of measurements, divided by the mean of the two measurements.

Table 2 Blood pressure and echocardiographic variables (mean \pm s.D.) in the study groups.

\begin{tabular}{|c|c|c|c|c|c|}
\hline & \multirow[b]{2}{*}{$\begin{array}{c}\text { Controls } \\
n=51\end{array}$} & \multicolumn{2}{|c|}{ PHPT cases } & \multicolumn{2}{|c|}{$\boldsymbol{P}$} \\
\hline & & $\begin{array}{c}\text { Baseline } \\
n=51 \\
\text { (35 females) }\end{array}$ & $\begin{array}{c}\text { Follow-up } \\
n=50 \\
\text { (34 females) }\end{array}$ & $\begin{array}{l}\text { PHPT baseline } \\
\text { versus controls }\end{array}$ & $\begin{array}{l}\text { PHPT baseline } \\
\text { versus follow-up }\end{array}$ \\
\hline $\mathrm{BP}$ at rest, systolic $(\mathrm{mmHg})$ & $119.6 \pm 12.6$ & $127.6 \pm 17.1$ & $124.6 \pm 16.6$ & $<0.05$ & $<0.05$ \\
\hline $\mathrm{BP}$ at rest, diastolic $(\mathrm{mmHg})$ & $76.1 \pm 7.7$ & $80.3 \pm 9.6$ & $78.4 \pm 8.6$ & NS & $<0.05$ \\
\hline Heart rate at rest (per min) & $61 \pm 9$ & $62 \pm 10$ & $60 \pm 9$ & NS & NS \\
\hline RVDd (cm) & $2.77 \pm 0.41$ & $2.70 \pm 0.36$ & $2.77 \pm 0.36$ & NS & NS \\
\hline LVDd (cm) & $4.89 \pm 0.41$ & $4.94 \pm 0.40$ & $4.94 \pm 0.40$ & NS & NS \\
\hline LVDs (cm) & $3.12 \pm 0.40$ & $3.12 \pm 0.37$ & $3.15 \pm 0.33$ & NS & NS \\
\hline Left atrial area $\left(\mathrm{cm}^{2}\right)$ & $19.20 \pm 2.80$ & $19.91 \pm 3.08$ & $19.94 \pm 2.55$ & NS & NS \\
\hline IVS (cm) & $0.91 \pm 0.13$ & $0.94 \pm 0.16$ & $0.96 \pm 0.15$ & NS & NS \\
\hline PWT (cm) & $0.86 \pm 0.16$ & $0.88 \pm 0.11$ & $0.86 \pm 0.13$ & NS & NS \\
\hline RWT $(\mathrm{cm})$ & $0.36 \pm 0.05$ & $0.37 \pm 0.05$ & $0.37 \pm 0.05$ & NS & NS \\
\hline \multicolumn{6}{|l|}{ LVMI $\left(\mathrm{g} / \mathrm{m}^{2}\right)$} \\
\hline Males & $93.7 \pm 11.7$ & $99.3 \pm 18.4$ & $98.4 \pm 16.0$ & NS & NS \\
\hline Females & $80.6 \pm 20.1$ & $81.8 \pm 12.3$ & $80.4 \pm 14.8$ & NS & NS \\
\hline
\end{tabular}

BP, blood pressure; RVDd, right ventricular end-diastolic dimension; LVDd, left ventricular end-diastolic dimension; LVDs, left ventricular end-systolic dimension; IVS, interventricular septum thickness; PWT, left ventricular posterior wall thickness; RWT, relative wall thickness; LVM, left ventricular mass; LVMI, left ventricular mass index. 
The CV for DTI-assessed myocardial velocities was $3-4 \%$ for inter-observer and 2-3\% for intra-observer analyses. The $\mathrm{CV}$ for transmitral flow velocities were $2-4 \%$ for inter-observer and $1-2 \%$ for intra-observer. The CV for M-mode AV-plane displacement was 2-4\% for inter-observer and 2-3\% for intra-observer analyses.

\section{Statistical analysis}

The sample size was based on differences and s.D. of diastolic function from earlier studies to guarantee a power level of $80 \%$ at a confidence level of 95\% (20, 21). Statistical analysis was performed with the SPSS for Windows statistical package 17.0 (SPSS Inc., Chicago, IL, USA). Data are expressed as mean \pm s.D. Comparisons between the group of patients at baseline and the control group were performed with the Mann-Whitney $U$ test for unpaired data. Wilcoxon signed rank sum test was used for intra-individual analyses. Relationships between variables were assessed with Spearman's $\rho$ correlation test. All tests were done two-tailed, and $P<0.05$ was considered to be statistically significant.

\section{Results}

\section{Clinical and biochemical results}

Forty-eight patients had a single parathyroid adenoma removed; three patients had multiglandular disease. Normocalcemia was achieved in 49 of 51 patients after the first PTX; the other two patients became normocalcemic after a second operation when a second parathyroid adenoma and an intrathyroidal adenoma respectively were removed. All patients were normocalcemic at the postoperative follow-up 1 month after PTX (not shown). There were no PTX-related complications. The mean total wet weight of the excised abnormal parathyroid tissue was $619 \pm 837 \mathrm{mg}$. The patients were re-examined a mean of $15 \pm 4$ (median 14.8) months after successful PTX. Three patients were re-examined $<1$ year after surgery $(7,10$, and 11 months respectively). At the follow-up, PTH levels were slightly elevated (mean $78 \pm 9 \mathrm{ng} / \mathrm{l}$ ) in combination with normal serum calcium (mean $\mathrm{Ca}^{++} 1.24 \pm 0.04 \mathrm{mM} / \mathrm{l}$ ) in seven cases. $\mathrm{Ca}^{++}$was elevated in two cases (one woman on vitamin D treatment with $1.45 \mathrm{mM} / \mathrm{l} \mathrm{Ca}^{++}$and $37 \mathrm{ng} / \mathrm{l}$ PTH in whom $\mathrm{Ca}^{++}$normalized after discontinuation of vitamin $\mathrm{D}$ and another woman with $1.36 \mathrm{mM} / \mathrm{l} \mathrm{Ca}^{++}$ and $62 \mathrm{ng} / \mathrm{l} \mathrm{PTH})$. Clinical and biochemical data of patients and controls are given at baseline and after PTX in Table 1. Plasma-intact PTH, calcium, and serum $\mathrm{Ca}^{++}$were significantly higher in patients at baseline compared to healthy controls, while plasma phosphate levels were significantly lower (Table 1). PTH, calcium, and phosphate concentrations normalized after PTX and did not differ from controls at the follow-up visit (Table 1). All subjects fulfilled the BP criteria (SBP $\leq 140$ and DBP $\leq 90 \mathrm{mmHg}$ ) before inclusion. At baseline measurements, SBP was $>140 \mathrm{mmHg}$ in 11 patients and 4 controls (range of all subjects is $180-95 \mathrm{mmHg}$ ), and DBP was $>90 \mathrm{mmHg}$ in 9 patients (range of all subjects is $110-55 \mathrm{mmHg}$ ). SBP was significantly higher in the PHPT group compared to controls and decreased after PTX (Table 2). SBP correlated to the age $(r=0.45$; $P<0.001)$ as well as to the levels of PTH $(r=0.26$; $P<0.01$, Fig. 1a) and $\mathrm{Ca}^{++}(r=0.25 ; P<0.05$, Fig. 1b). DBP decreased after PTX (Table 2).

BMI increased after PTX only in female PHPT $\left(23.5 \pm 2.7\right.$ vs $\left.24.3 \pm 3.3 \mathrm{~kg} / \mathrm{m}^{2}, P<0.01\right)$, but not in male PHPT $\left(25.3 \pm 3.0\right.$ vs $\left.25.6 \pm 3.7 \mathrm{~kg} / \mathrm{m}^{2}, P=\mathrm{NS}\right)$. In female PHPT, the weight of the excised abnormal parathyroid tissue correlated to the PTH but not to $\mathrm{Ca}^{++}(r=0.52 ; \mathrm{P}<0.001)$. Among men, there was a strong correlation between adenoma weight and $\mathrm{Ca}^{++}$ $(r=0.89 ; P<0.01)$ but not to PTH. The phosphate level
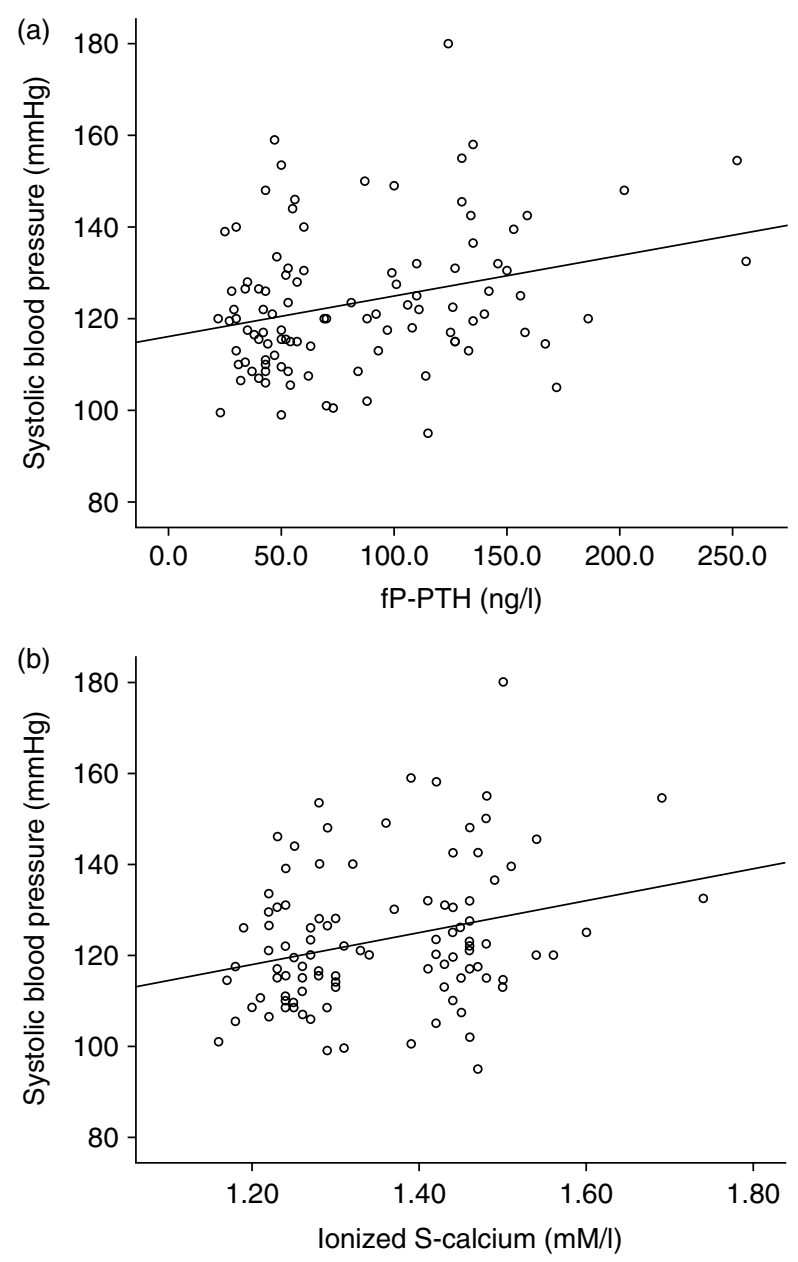

Figure 1 Systolic blood pressure for the whole group of PHPT patients and the healthy control subjects was correlated to (a) the PTH level $(r=0.26 ; P<0.01)$ and to $(b)$ the ionized calcium level $(r=0.25 ; P<0.05)$. 
Table 3 Systolic and diastolic function variables (mean \pm S.D.) by echocardiography and Doppler tissue imaging at baseline and follow-up. The values are mean \pm s.D.

\begin{tabular}{|c|c|c|c|c|c|}
\hline \multirow[b]{2}{*}{ Variable } & \multirow[b]{2}{*}{$\begin{array}{c}\text { Controls } \\
n=51\end{array}$} & \multicolumn{2}{|c|}{ PHPT cases } & \multicolumn{2}{|c|}{$P$} \\
\hline & & $\begin{array}{c}\text { Baseline } \\
n=51 \\
\text { (35 females) }\end{array}$ & $\begin{array}{c}\text { Follow-up } \\
n=50 \\
\text { (34 females) }\end{array}$ & $\begin{array}{l}\text { PHPT baseline } \\
\text { versus controls }\end{array}$ & $\begin{array}{l}\text { PHPT baseline } \\
\text { versus follow-up }\end{array}$ \\
\hline \multicolumn{6}{|l|}{ Systolic variable } \\
\hline DTI-RV systolic velocity $(\mathrm{cm} / \mathrm{s})(13.5 \pm 1.7)^{\mathrm{a}}$ & $13.85 \pm 1.77$ & $14.23 \pm 1.85$ & $13.48 \pm 1.79$ & NS & $<0.05$ \\
\hline DTI-IVS systolic velocity $(\mathrm{cm} / \mathrm{s})(7.7 \pm 1.7)^{b}$ & $8.23 \pm 1.00$ & $8.48 \pm 0.96$ & $7.97 \pm 0.85$ & NS & $<0.05$ \\
\hline DTI-LVL systolic velocity $(\mathrm{cm} / \mathrm{s})(8.5 \pm 2.2)^{\mathrm{b}}$ & $9.80 \pm 1.89$ & $9.61 \pm 2.05$ & $8.87 \pm 1.63^{\star}$ & NS & $<0.05$ \\
\hline Ejection fraction (\%) & $65.29 \pm 6.17^{c}$ & $66.18 \pm 5.78^{\mathrm{c}}$ & $65.75 \pm 4.84^{\mathrm{C}}$ & NS & NS \\
\hline Fractional shortening (\%) & $36.29 \pm 5.14^{\mathrm{c}}$ & $37.02 \pm 4.33^{\mathrm{C}}$ & $36.46 \pm 3.81^{\mathrm{c}}$ & NS & NS \\
\hline AV-plane RV (cm) & $2.64 \pm 0.32$ & $2.58 \pm 0.37$ & $2.50 \pm 0.39$ & NS & NS \\
\hline AV-plane IVS (cm) & $1.44+0.20$ & $1.42+0.18$ & $1.39+0.19$ & NS & NS \\
\hline AV-plane LV (cm) & $1.57 \pm 0.21$ & $1.55 \pm 0.18$ & $1.55 \pm 0.18$ & NS & NS \\
\hline \multicolumn{6}{|l|}{ Diastolic variable } \\
\hline$E$-wave $(\mathrm{cm} / \mathrm{s})$ & $80.18 \pm 14.44$ & $75.76 \pm 15.09$ & $75.77 \pm 13.47$ & NS & NS \\
\hline$A$-wave $(\mathrm{cm} / \mathrm{s})$ & $59.59 \pm 12.48$ & $60.58 \pm 15.27$ & $61.41 \pm 12.70$ & NS & NS \\
\hline$E / A$ & $1.39+0.33$ & $1.30+0.34$ & $1.27+0.28$ & NS & NS \\
\hline DT (ms) & $197.9 \pm 22.6$ & $199.7 \pm 27.9$ & $200.8 \pm 29.3$ & NS & NS \\
\hline Isovolumic relaxation time (ms) & $82.36 \pm 16.20$ & $86.67 \pm 18.42$ & $86.32 \pm 19.42$ & NS & NS \\
\hline PVs/PVd & $1.16 \pm 0.27$ & $1.22 \pm 0.34$ & $1.21 \pm 0.32$ & NS & NS \\
\hline$E / E^{\prime}$ Septal & $7.81+1.73$ & $7.69+1.74$ & $7.54+1.58$ & NS & NS \\
\hline$E / E^{\prime}$ Lateral & $6.38 \pm 1.43$ & $6.35 \pm 1.84$ & $6.50 \pm 1.61$ & NS & NS \\
\hline
\end{tabular}

DTI, Doppler tissue imaging; AV-plane, atrioventricular plane displacement; RV, right ventricular wall; LVL, left ventricular lateral wall; IVS, interventricular septum; $E$-wave, early transmitral diastolic flow velocity; $A$-wave, flow velocity during atrial contraction; DT, deceleration time; PVs, systolic pulmonary vein velocity; PVd, diastolic pulmonary vein velocity; $E / E^{\prime}$, a ratio of early transmitral diastolic flow velocity $(E)$ and early diastolic velocity recorded by $D T I$ ( $E^{\prime}$ ) in the mitral annulus. ${ }^{*}$ The peak systolic velocity in the lateral part of the mitral annulus was lower in patients after PTX compared to controls, $P<0.05$.

${ }^{a}$ Indicates the reference for published DTI values for RV (22).

${ }^{b}$ Indicates the reference for published DTI values for LV (23).

${ }^{\mathrm{c}} n=49-50$

$(0.87 \pm 0.16$ vs $0.76 \pm 0.13 \mathrm{mM} / \mathrm{l}, \quad P<0.05)$ was higher in the female group of PHPT compared to male PHPT patients.

\section{Echocardiographic results}

There were no differences between the groups in the variables describing cardiac dimensions and structure (Table 2). The systolic and diastolic LV function evaluated by Doppler echocardiography was within normal limits, and there were no differences between the groups at baseline (Table 3 ). The regional peak systolic myocardial velocities $\left(S^{\prime}\right)$ measured with DTI in the base of the RVs and LVs decreased after PTX (Table 3). For variables with a significant change after PTX, we also tested post-PTX results for possible differences compared to the control group. Compared to our age- and gender-matched healthy controls, the PHPT group had numerically lower peak systolic velocities after PTX, but the difference reached a statistical significance only in the lateral part of the mitral annulus (Table 3). For comparison, previously published normal values for DTI myocardial velocities for RVs and LVs are shown in Table $3(22,23)$. The values are in the same range as in our healthy control group.

The peak systolic velocity of the septal part of the mitral annulus correlated significantly and positively to the $\mathrm{Ca}^{++}$level $(r=0.4 ; \mathrm{P}<0.05)$ in the PHPT group at baseline. IVRT was increased in the male PHPT group compared to female PHPT and the healthy controls $(97 \pm 20$ vs $82 \pm 15,84 \pm 13, P<0.05)$. The $E / A$ ratio was inversely correlated to the PTH level $(r=-0.33$; $P<0.01)$, SBP $(r=-0.40 ; P<0.01)$, and DBP $(r=-0.46 ; P<0.01)$.

\section{Discussion}

The present study was conducted to evaluate cardiac function and the effect of PTX in patients with mild PHPT. The main strength of our study is the strict design, excluding PHPT patients with known cardiovascular risk factors. The PHPT patients included in this study made up about one-tenth of all the PHPT patients treated with PTX at our clinic during the time period. Men made up $31 \%$ of our study cohort compared with $22 \%$ of our unselected control cohort. We observed no differences in global systolic or diastolic function, or cardiac morphology, in our PHPT patients compared to the age-matched healthy controls. The regional peak systolic myocardial velocities in the RVs and LVs in our study correspond to normal values described previously $(22,23)$. However, the PHPT patients did show a significant decrease in $\mathrm{BP}$ and regional peak systolic myocardial velocities after PTX. In one site, the regional peak systolic myocardial velocities were significantly lower in patients after PTX compared to healthy controls. Our results indicate that patients with mild PHPT without any other known cardiovascular risk factors 
have a higher systolic myocardial performance at baseline, which seems to be associated with the level of PTH and $\mathrm{Ca}^{++}$. The clinical significance of these findings is not clear. Hypothetically, a disease-related inotropic effect may result in increased vascular resistance and in an increased cardiac workload. Our hypothesis is supported by the results of a study that compared patients with mild PHPT randomized to PTX either directly or after 1 year of observation (24). In that study, some of the systolic and diastolic function parameters decreased after PTX when the PTH and calcium levels had normalized. The functional changes observed were transient, and the values in question returned to preoperative levels within 1 year. This reaction pattern was interpreted as a withdrawal inotropic effect of PTH. The authors also found higher LVMI in the group of patients followed without surgery, and the extent of the LVMI increase was associated with PTH. These findings support our hypothesis of a suprasystolic performance that may promote cardiac hypertrophy and morbidity. Cook et al. (25) concluded, from a longitudinal cohort study, that a small reduction of $2 \mathrm{mmHg}$ in DBP in the population, in addition to medical treatment, could have a major public health impact on the risk of coronary heart disease and of stroke events. Only a few studies have reported a decrease in BP after PTX (5, 12). Recently, Bollerslev et al. (12) have reported, from a randomized study, declines in BP in both surgical and observation groups of PHPT patients with mild hypercalcemia.

To our knowledge, DTI has only been used once before to evaluate cardiac function in PHPT patients. Baycan et al. (26) reported small differences in some variables of diastolic function in PHPT patients without hypertension, diabetes mellitus, and coronary artery disease. Similar to Baycan et al., we observed prolonged IVRT in our study, but only in the male PHPT group in comparison to female PHPT and healthy male controls. We also found an inverse correlation between $E / A$ ratio and PTH. The clinical importance of these subtle findings is unclear, but they may represent signs of early diastolic dysfunction.

Available data on the extent and reversibility of cardiovascular morbidity in PHPT and the coupling to biochemical disturbances are conflicting (15). Based on a large population study, Kamycheva et al. (27) reported serum PTH to be an independent predictor of coronary heart disease in both sexes. Bergenfelz et al. (28) concluded that a normal PTH level in PHPT is associated with a milder form of disease and smaller adenomas, while the calcium level did not reflect disease severity. Recently, Walker et al. (29) have reported subclinical carotid vascular manifestations in mild PHPT associated with the extent of PTH elevation. The duration of the disease is probably an important prognostic factor, suggesting benefits of early surgical cure of mild PHPT before irreversible cardiovascular manifestations may occur $(5,29)$.
To conclude, our results indicate that patients with PHPT without cardiovascular risk factors have a normal cardiac morphology and function. The BP and the systolic velocities were marginally reduced after PTX but reflected the values of the control group. Our findings warrant further investigation of the clinical and prognostic significance of these possibly diseaserelated inotropic effects.

\section{Declaration of interest}

The authors declare that there is no conflict of interest that could be perceived as prejudicing the impartiality of the research reported.

\section{Funding}

This study was supported by grants from the Stockholm County Council, Karolinska Institutet, the Swedish Heart Lung Foundation, the Swedish Medical Research Council, Capio Research Foundation, and the Fredrik and Ingrid Thuring Foundation.

\section{References}

1 Marx SJ. Hyperparathyroid and hypoparathyroid disorders. New England Journal of Medicine 2000343 1863-1875.

2 Lundgren E, Hagstrom EG, Lundin J, Winnerback K, Roos J, Ljunghall S \& Rastad J. Primary hyperparathyroidism revisited in menopausal women with serum calcium in the upper normal range at population-based screening 8 years ago. World Journal of Surgery 200226 931-936.

3 Bilezikian JP, Khan AA \& Potts JT Jr. Guidelines for the management of asymptomatic primary hyperparathyroidism: summary statement from the third international workshop. Journal of Clinical Endocrinology and Metabolism 200994 335-339.

4 Barletta G, De Feo ML, Del Bene R, Lazzeri C, Vecchiarino S, La Villa G, Brandi ML \& Franchi F. Cardiovascular effects of parathyroid hormone: a study in healthy subjects and normotensive patients with mild primary hyperparathyroidism. Journal of Clinical Endocrinology and Metabolism 200085 1815-1821.

5 Dalberg K, Brodin LA, Juhlin-Dannfelt A \& Farnebo LO. Cardiac function in primary hyperparathyroidism before and after operation. An echocardiographic study. European Journal of Surgery 1996162 171-176.

6 Hagstrom E, Lundgren E, Lithell H, Berglund L, Ljunghall S, Hellman P \& Rastad J. Normalized dyslipidaemia after parathyroidectomy in mild primary hyperparathyroidism: populationbased study over five years. Clinical Endocrinology 200256 $253-260$.

7 Nilsson IL, Aberg J, Rastad J \& Lind L. Endothelial vasodilatory dysfunction in primary hyperparathyroidism is reversed after parathyroidectomy. Surgery 1999126 1049-1055.

8 Piovesan A, Molineri N, Casasso F, Emmolo I, Ugliengo G, Cesario F \& Borretta G. Left ventricular hypertrophy in primary hyperparathyroidism. Effects of successful parathyroidectomy. Clinical Endocrinology 199950 321-328.

9 Stefenelli T, Abela C, Frank H, Koller-Strametz J, Globits S, BerglerKlein J \& Niederle B. Cardiac abnormalities in patients with primary hyperparathyroidism: implications for follow-up. Journal of Clinical Endocrinology and Metabolism 199782 106-112.

10 Walker MD \& Silverberg SJ. Cardiovascular aspects of primary hyperparathyroidism. Journal of Endocrinological Investigation 2008 31 925-931.

11 Yu N, Donnan PT, Flynn RWV, Murphy MJ, Smith D, Rudman A \& Graham PL. Increased mortality and morbidity in mild primary hyperparathyroid patients. Clinical Endocrinology 2010 73 30-34. 
12 Bollerslev J, Rosen T, Mollerup CL, Nordenstrom J, Baranowski M, Franco C, Pernow Y, Isaksen GA, Godang K, Ueland T \& Jansson S. Effect of surgery on cardiovascular risk factors in mild primary hyperparathyroidism. Journal of Clinical Endocrinology and Metabolism 200994 2255-2261.

13 Lundgren E, Lind L, Palmer M, Jakobsson S, Ljunghall S \& Rastad J. Increased cardiovascular mortality and normalized serum calcium in patients with mild hypercalcemia followed up for 25 years. Surgery 2001130 978-985.

14 Nilsson IL, Yin L, Lundgren E, Rastad J \& Ekbom A. Clinical presentation of primary hyperparathyroidism in Europe - nationwide cohort analysis on mortality from nonmalignant causes. Journal of Bone and Mineral Research 200217 (Suppl 2) N68-N74.

15 Soreide JA, van Heerden JA, Grant CS, Yau Lo C, Schleck C \& Ilstrup DM. Survival after surgical treatment for primary hyperparathyroidism. Surgery 1997122 1117-1123.

16 Wermers RA, Khosla S, Atkinson EJ, Grant CS, Hodgson SF, O'Fallon WM \& Melton LJ III. Survival after the diagnosis of hyperparathyroidism: a population-based study. American Journal of Medicine $1998 \mathbf{1 0 4} 115-122$.

17 Lang RM, Bierig M, Devereux RB, Flachskampf FA, Foster E, Pellikka PA, Picard MH, Roman MJ, Seward J, Shanewise JS, Solomon SD, Spencer KT, Sutton MS \& Stewart WJ. Recommendations for chamber quantification: a report from the American Society of Echocardiography's Guidelines and Standards Committee and the Chamber Quantification Writing Group, developed in conjunction with the European Association of Echocardiography, a branch of the European Society of Cardiology. Journal of the American Society of Echocardiography 200518 1440-1463.

18 Sahn DJ, DeMaria A, Kisslo J \& Weyman A. Recommendations regarding quantitation in M-mode echocardiography: results of a survey of echocardiographic measurements. Circulation $1978 \mathbf{5 8}$ 1072-1083.

19 Levy D, Savage DD, Garrison RJ, Anderson KM, Kannel WB \& Castelli WP. Echocardiographic criteria for left ventricular hypertrophy: the Framingham Heart Study. American Journal of Cardiology 198759 956-960.

20 Govind S, Brodin LA, Nowak J, Quintana M, Raumina S, Ramesh SS, Keshava R \& Saha S. Isolated type 2 diabetes mellitus causes myocardial dysfunction that becomes worse in the presence of cardiovascular diseases: results of the myocardial doppler in diabetes (MYDID) study 1. Cardiology 2005103 189-195.
21 Nilsson IL, Aberg J, Rastad J \& Lind L. Left ventricular systolic and diastolic function and exercise testing in primary hyperparathyroidism-effects of parathyroidectomy. Surgery 2000128 895-902.

22 Innelli P, Esposito R, Olibet M, Nistri S \& Galderisi M. The impact of ageing on right ventricular longitudinal function in healthy subjects: a pulsed tissue Doppler study. European Journal of Echocardiography $200910491-498$.

23 Innelli P, Sanchez R, Marra F, Esposito R \& Galderisi M. The impact of aging on left ventricular longitudinal function in healthy subjects: a pulsed tissue Doppler study. European Journal of Echocardiography 20089 241-249.

24 Almqvist EG, Bondeson AG, Bondeson L, Nissborg A, Smedgard P \& Svensson SE. Cardiac dysfunction in mild primary hyperparathyroidism assessed by radionuclide angiography and echocardiography before and after parathyroidectomy. Surgery 2002132 1126-1132 discussion 1132 .

25 Cook NR, Cohen J, Hebert PR, Taylor JO \& Hennekens CH. Implications of small reductions in diastolic blood pressure for primary prevention. Archives of Internal Medicine 1995155 701-709.

26 Baykan M, Erem C, Erdogan T, Ersoz HO, Gedikli O, Korkmaz L, Kucukosmanoglu M, Haclhasanoglu A, Kaplan S \& Celik S. Assessment of left ventricular diastolic function and the Tei index by tissue Doppler imaging in patients with primary hyperparathyroidism. Clinical Endocrinology 200766 483-488.

27 Kamycheva E, Sundsfjord J \& Jorde R. Serum parathyroid hormone levels predict coronary heart disease: the Tromso Study. European Journal of Cardiovascular Prevention and Rehabilitation 200411 69-74.

28 Bergenfelz A, Lindblom P, Lindergard B, Valdemarsson S \& Westerdahl J. Preoperative normal level of parathyroid hormone signifies an early and mild form of primary hyperparathyroidism. World Journal of Surgery $2003 \mathbf{2 7} 481-485$.

29 Walker MD, Fleischer J, Rundek T, McMahon DJ, Homma S, Sacco R \& Silverberg SJ. Carotid vascular abnormalities in primary hyperparathyroidism. Journal of Clinical Endocrinology and Metabolism 200994 3849-3856.

Received 11 June 2010

Accepted 18 June 2010 